Original Article

\title{
CLINICAL INTERVENTIONS UNDERTAKEN BY FINAL YEAR STUDENT PHARMACISTS ON ROUNDING TEAMS IN NIGERIA: A 3-YEAR CROSS-SECTIONAL EVALUATION
}

\author{
EBERE EMILIA AYOGU ${ }^{*}$, ABDULMUMINU ISAH ${ }^{1}$, MAXWELL OGOCHUKWU ADIBE1
}

1Department of Clinical Pharmacy and Pharmacy Management, University of Nigeria, 410001, Nsukka, Enugu State Email: ebere.ayogu@unn.edu.ng

Received: 05 Jun 2018 Revised and Accepted: 24 Jul 2018

\begin{abstract}
Objective: The aim of this study was to assess the interventions of final year pharmacy students of University of Nigeria Nsukka (UNN) during clinical ward rounds in a secondary and a tertiary hospital in Enugu State, Nigeria.

Methods: Students were instructed at the start of their clerkship by pharmacist preceptors on how to appropriately document clinical interventions across the hospitals. A pharmacist reviewed each intervention entered by the students for appropriateness. All data collected were entered into the IBM Statistical Products and Service Solutions (SPSS) for Windows, Version 21.0 for analysis. Descriptive statistics, including mean and percentages, were used to analyze data obtained. Ethical approval was obtained from the Health Research and Ethics committee of the University of Nigeria
\end{abstract} Teaching Hospital (UNTH), Ituku-Ozalla, Enugu State.

Results: The students documented interventions for three hundred and eight (308) patients. There were more females among the patients (157) and most were aged 19-35 y (92). The common types of interventions performed were drug-drug interactions (14\%), therapeutic duplication (11\%), and patient and family education (11.7\%). The most common additional laboratory test recommended was Serum-Electrolyte-UreaCreatinine (SEUCr) (30.77\%). The most common form of patient education rendered was on dietary and lifestyle modifications in ulcer (1.9\%). No characteristic of the patients had a statistically significant relationship with the types and frequency of clinical interventions.

Conclusion: Final year pharmacy students of UNN demonstrated competencies in experiential education. They were able to make valid clinical interventions that contributed to patient care in the two hospitals during their clinical clerkship.

Keywords: Clinical clerkship, Pharmacy students, Drug therapy problems

(c) 2018 The Authors. Published by Innovare Academic Sciences Pvt Ltd. This is an open access article under the CC BY license (http://creativecommons.org/licenses/by/4.0/) DOI: http://dx.doi.org/10.22159/ijpps.2018v10i9.27754

\section{INTRODUCTION}

Rational use of medicines is used by the World Health Organization (WHO) to refer to when patients receive medications that are individualized in doses appropriate to their clinical conditions for an adequate period of time, which they should get at the lowest possible cost to them and their community $[1,2]$. This Expert Committee definition infers that rational drug use involves both the prescription and dispensing of the right drug to the right patient. The WHO estimates that half of the medicines prescribed, dispensed and sold are inappropriate and half of all patients take their drugs incorrectly. This inappropriate use of medicines has no regional bias: studies have proven that it is a global healthcare problem, especially in the developing countries [3-5]. A salient implication of the definition by WHO is that rational use of medicines has medical, social and economic effects on the patients, and by extension, their communities. About $75 \%$ of the world population lives in the developing countries, $25-50 \%$ of whom have little or no access to essential medicine[6, 7]. Those countries have weak healthcare systems that have little or no capacity to monitor drug use adequately.

Medication errors occur more frequently than expected. A mean prescription error rate of $28.7 \%$ was recorded in a retrospective study in Nigeria [8], although a higher rate of $76.3 \%$ was recorded two years earlier [9]. Still in Nigeria, the incidence of self-reported medication error among doctors, pharmacists and nurses was $47 \%$ [10]. Lazarou et al. reported that in 1994 in US, fatal adverse drug events (ADEs) were the sixth leading cause of death. They also reported that $10.9 \%$ of all inpatients experience some ADEs, while $2.1 \%$ of admissions resulted in serious events[11]. Most medications errors occur at the point of selecting therapeutic plans for the patients $[12,13]$. The importance of adding the expertise of a clinical pharmacist on the rounding process has been proposed as a way of addressing the occurrence of medication errors. This stemmed from the fact that lack of adequate information primarily about the therapeutic agent as well as the patients contributes a lot to medication errors. In the intensive care unit (ICU) alone, the inclusion of a pharmacist on a rounding team reduced the incidence of ADEs by two-thirds [14].

The rational use of the drug is important to ensure that those that have access to medicines optimally utilize them. This requires interventions at the points of prescription and dispensing of medicines. A Clinical intervention refers to an intentional action that is appropriately designed to produce a desired health-related outcome, thereby creating research evidence and knowledge [15]. Clinical intervention can be initiated by any health professional. The pharmacist is uniquely positioned between the prescriber and the patient. A pharmacist-initiated intervention can prevent or resolve the prescription error and even dispensing error [16-19]. Over the years, Pharmacy practice has evolved from the traditional roles of drug dispensing and compounding to a more proactive approach to patient care. This involves the optimization of medication therapy and promoting health, wellness, and disease prevention through pharmaceutical care. The growth of Pharmacy practice has led to a need for modification of the training and educational requirements of pharmacists. Hence, training beyond didactic lectures in class is required, and is best achieved through clerkship/clinical rotation in hospitals. In Nigeria, the rotation is conducted in the final semester of undergraduate Pharmacy studies for about 3 mo [20]. Students undergoing clerkship are expected to rotate round all units in the hospital, learning skills that were not acquired through didactic lectures. The goal of the clerkship programme is to equip students with clinical skills, knowledge and professional behaviours necessary to care for the patient. It also furnishes them with the ability to identify and resolve drug-related problems through patient information retrieval and assessment. The several contributions of pharmacy students to patient care in the US have been mentioned to include the provision of patient education, optimization of 
pharmaceutical care for patients, and provision of information to other healthcare providers [21]. To optimize their contributions preparatory to their future role as pharmacists, the American Council for Pharmacy Education (ACPE) recommends that the nature and extent of students' interactions with patients and other healthcare professionals should be documented and assessed.

The impact of pharmacy students at clinical rotations in different practice settings has been evaluated in a number of studies [22-31]. The studies measured the types and significance of the students' clinical interventions, and the cost-saving implications to the institution [21]. The primary purpose of our study was to assess student pharmacists' interventions during clinical ward rounds in a secondary and a tertiary hospital in Enugu State, Nigeria. This study is the first of its kind to be carried out in Nigeria since the inception of clerkship in Nigerian Pharmacy schools.

\section{MATERIALS AND METHODS}

\section{Methods}

This study involved a cross-sectional review of clinical interventions by final year students of University of Nigeria Nsukka (UNN) for three years (2015-2017). They completed a 3-month clerkship each year at a secondary hospital (Bishop Shanahan Hospital, BSH, Nsukka) and a tertiary hospital (University of Nigeria Teaching Hospital, UNTH, Enugu) in Enugu State, Nigeria. As part of the clerkship, students participated in teams during clinical activities to optimize medication therapy management and patient safety. Each team is allowed access to the patient folder after clinical rotation for medication evaluation and onward report of any finding to their preceptors who supervised all clerkship activities in the hospital. The students were required to document all clinical activities performed, which served as a learning tool for the students on how pharmacists keep track of clinical interventions. Clinical interventions involved written and verbal interactions with other healthcare professionals, patients, and caregivers, and were documented on a paper data collection form for the period of the study. An intervention documentation pro forma, following the interventions identified by Leape et al. was prepared for the pharmacists. The form captured medication error based on the intervention types to include: (1) drug-drug interaction, (2) lack of patient education, (3) recommendation of alternative therapeutic course, (4) identification of drug allergy, (5) wrong patient, (6) inappropriate dosage/frequency, (7) approval of non-formulary use of a drug, (8) additional medication, (9) patients education, (10) additional laboratory, and (11) drug/food interaction [14, 32].

Students were instructed at the start of their clerkship by pharmacist preceptors on how to appropriately document clinical interventions using the documentation instrument in use and this training was consistent over time and across the two hospitals. A pharmacist preceptor reviewed each intervention entered by the students for appropriateness and accuracy of documentation.

The analysis included data from all student pharmacists in both hospitals who were trained on intervention documentation and whose intervention was approved by the pharmacist preceptor as being valid. All data collected were collated and entered into the IBM Statistical Products and Service Solutions (SPSS) for Windows, Version 21.0 by pharmacist preceptors for analysis. Descriptive statistics, including mean and percentages, were used to analyze data obtained. This study was conducted after obtaining ethical approval from the Health Research and Ethics committee of the University of Nigeria Teaching Hospital (UNTH), Ituku-Ozalla, Enugu State.

Table 1: Characteristics of the patients

\begin{tabular}{llc}
\hline & Frequency & Percentage \\
\hline Age (Years) & & \\
$\leq 6$ & 46 & 14.9 \\
$7-18$ & 47 & 15.3 \\
$19-35$ & 92 & 29.9 \\
$36-50$ & 61 & 19.8 \\
$\geq 51$ & 62 & 20.1 \\
Total & 308 & 100.0 \\
Gender & 151 & 49.0 \\
Male & 157 & 51.0 \\
Female & 308 & 100.0 \\
Total & & \\
\hline
\end{tabular}

Table 2: Clinical interventions by the student pharmacists

\begin{tabular}{|c|c|c|}
\hline & Frequency & Percentage \\
\hline No indication/discontinue medication & 24 & 7.8 \\
\hline Alternative/additional medication & 26 & 8.4 \\
\hline Antibiotic recommendations & 5 & 1.6 \\
\hline Duration of therapy & 22 & 7.1 \\
\hline Inappropriate dosage/frequency & 30 & 9.7 \\
\hline Incorrect route/rate/time of administration & 3 & 1.0 \\
\hline Pharmacokinetic monitoring & 22 & 7.1 \\
\hline Additional labs indicated & 29 & 9.4 \\
\hline Adverse drug event & 3 & 1.0 \\
\hline Therapeutic duplication & 40 & 13.0 \\
\hline Drug interaction & 43 & 14.0 \\
\hline Allergy clarification/prevention & 4 & 1.3 \\
\hline Contra-indication to therapy & 8 & 2.6 \\
\hline Medication identification & 2 & 0.6 \\
\hline Wrong patient & 1 & 0.3 \\
\hline Patient/family education & 36 & 11.7 \\
\hline Drug information & 6 & 1.9 \\
\hline Parenteral to oral route conversion & 2 & 0.6 \\
\hline Indication without therapy & 2 & 0.6 \\
\hline Total & 308 & 100.0 \\
\hline
\end{tabular}


Table 3: Additional laboratory tests recommended during the interventions

\begin{tabular}{lll}
\hline & Frequency & Percentage \\
\hline Microbial culture and sensitivity & 5 & 17.24 \\
CD4 count & 2 & 6.90 \\
MP & 5 & 17.24 \\
MCS & 6 & 20.69 \\
SEUCr & 8 & 27.59 \\
GFR & 3 & 10.34 \\
Total & 34 & 100 \\
\hline
\end{tabular}

Table 4: Patient education provided by the students

\begin{tabular}{|c|c|c|}
\hline & Frequency & Percentage \\
\hline Blood sugar management & 3 & 8.33 \\
\hline Alcohol-metronidazole disulfiram effect & 4 & 11.11 \\
\hline Dietary and lifestyle modifications in ulcer & 6 & 16.67 \\
\hline Omeprazole-take $1 \mathrm{hr}$ before a meal & 2 & 5.56 \\
\hline Elevation of legs to reduce pedal oedema & 2 & 5.56 \\
\hline Metoclopramide-extrapyramidal side effect & 2 & 5.56 \\
\hline Insulin-ready source of glucose in case of hypoglycemia & 1 & 2.78 \\
\hline Advise on exclusive breastfeeding & 1 & 2.78 \\
\hline Lisinopril- a cough & 2 & 5.56 \\
\hline Asthma management & 2 & 5.56 \\
\hline Tramadol-side effects & 4 & 11.11 \\
\hline Carbamazepine-side effects & 2 & 5.56 \\
\hline Methyldopa-effect on sexual dysfunction & 2 & 5.56 \\
\hline Prednisolone-dose tapering & 3 & 8.33 \\
\hline Total & 36 & 100 \\
\hline
\end{tabular}

\section{RESULTS}

The students documented interventions for four hundred and thirtyone (431) patients, but three hundred and eight (308) were judged valid. There were more females among the patients (157) and most were aged 19-35 y (92) (table 1). The most common types of interventions performed were drug-drug interactions (14\%), therapeutic duplication (11\%), and patient and family education $(11.7 \%)$ (table 2). Common drugs involved in the interventions were furosemide (intravenous) (3.6\%), artesunate (intravenous) (2.9\%), ceftriaxone (intravenous) (2.6\%), and diclofenac (oral) $(2.6 \%)$. The most common additional laboratory test recommended was SerumElectrolyte-Urea-Creatinine (SEUCr) (30.77\%) (table 3). The most common form of patient education rendered was on dietary and lifestyle modifications in ulcer. (1.9\%) (table 4). No characteristic of the patients had a statistically significant relationship with the types and frequency of clinical interventions.

\section{DISCUSSION}

Practical education of Pharmacy students on clinical matters is frequently thought to be expensive and not cost-saving to the institutions where the students train. This study shows that students have an impact as it relates to both drug information provision and recommendations made during rotations. The study also establishes the importance of bedside teaching as proven in an Indian study [33]. Most interventions in this study were made about female patients. A similar result was reported in a study in the Netherland, where interventions about males accounted for 41\% [34]. A study in Oman also reported males to be less (42.9\%) [35]. Possible explanation is that female patients may be more interested in knowing about drugs, their indications and any drug therapy problems from pharmacists or that more females visit the hospital when sick than males hence are more on admission. In contrast, a study in Australia revealed that $78.9 \%$ of the patients were males [34, 36, 37].

The most common types of interventions performed were drug interactions, therapeutic duplication and patient/family education. This is in contrast with a study by Kucukarslan et al. where the most common interventions documented were dosing-related changes and recommendations to add a drug to the therapeutic course [32]. Most of the clinical interventions on drug interaction were potential and not actual drug interaction. However it is of paramount importance to point out these potential interactions as it will help in quick identification of adverse effects and immediate withdrawal of inciting drug in a case of actual adverse drug reaction.

The original aim of clinical pharmacy as a professional practice (and not just a health science) is providing pharmaceutical care which involves patient education. In this study, education on dietary/lifestyle modification and medication use for ulcer patients were the highest. This education is necessary as most patients may likely engage in self-medication with over the counter drugs which are mainly NSAIDs. Most ulcer patients may have had education on diet from the nurses or another health professional, hence educating them on the effects of some drugs such as ibuprofen and diclofenac on their system will help them avoid exacerbation of symptoms. Education of pharmacy students and clinical pharmacy residents, while providing valuable care component to patients and other health-care providers, can successfully be performed as shown by the results of our program implemented in a teaching hospital.

Therapeutic duplication was also observed among prescriptions that had two or three medicines that belong to the same class of drug for the same indication. This observation may be due to overtreatment by prescriber following a patient's complaint of symptom exacerbation. The practice would be condemned, if the prescriptions contain antibiotics [38].

The rate of drug information (DI) requests in this study was very low compared to an Iranian study among Clinical Pharmacy residents where $22.30 \%$ of all interventions were drug information requests [39]. Ideally, it is expected that clinical pharmacy program should fill the gap between practice and pharmaceutical information. Information on new drugs is usually received from pharmaceutical company representatives, which could sometimes be biased and misleading in clinical practice [40].

Some limitations are acknowledged in our study. Students may have documented only interventions they recollected based on the perceived favorable outcome on patient care, as recognized in another study [24]. In addition, they may have been more likely to document the interventions that got accepted. This may have underestimated the total clinical interventions performed. Student pharmacists' interventions were all performed under the 
supervision of the pharmacist preceptors. However, for some interventions, the students may have received assistance from the preceptor in performing the intervention. The number of interventions for which students received assistance against those that were student-driven was not quantified. The performance and documentation of clinical interventions by students helps to contribute to their active learning process and preparation as future pharmacists [21].

\section{CONCLUSION}

Final year pharmacy students of the University of Nigeria, Nsukka demonstrated competencies in experiential education. Their contributions to patient care were in collaboration with patients themselves, and other members of the healthcare team. Their major role was documented to be making pharmacotherapy recommendations to prescribers.

\section{AUTHORS CONTRIBUTIONS}

Ebere conceived and designed the study and analyzed and interpreted the data. Abdulmuminu drafted and revised the article while Maxwell participated in the data acquisition and drafting of the article. All authors approved the final version to be submitted.

\section{CONFLICTS OF INTERESTS}

Declared none

\section{REFERENCES}

1. World Health Organization. Promoting the rational use of medicines: core components; 2002. Available from: http://www.who.int/medicines/publications/policyperspectiv es/ppm05en.pdf. [Last accessed on 31 Dec 2017]

2. World Health Organization. The Rational Use of Drugs. Geneva; 1985. Available from: http://apps.who.int/medicinedocs/ documents/s17054e/s17054e.pdf. [Last accessed on 31 Dec 2017].

3. Ofori-Asenso R, Agyeman AA. Irrational use of a medicines-a summary of key concepts. Pharm (Basel, Switzerland); 2016. Available from: http://www.ncbi.nlm.nih.gov/pubmed/28970408. [Last accessed on 31 Dec 2017].

4. World Health Organization. Problems of irrational drug use session guide problems of irrational drug use session guide purpose and content; 2004. Available from: http://new.paho.org/hq/dmdocuments/2010/3_IrrationalSG. pdf. [Last accessed on 31 Dec 2017]

5. Alfa J, Adigwe OP. Rational use of medicines in nigeria: a critical review. J Biol; 2014. Available from: http://www.iiste.org/Journals/index.php/JBAH/article/viewFi le/14487/14797. [Last accessed on 31 Dec 2017]

6. Leisinger KM, Garabedian LF, Wagner AK. Improving access to medicines in low and middle income countries: corporate responsibilities in context. South Med Rev 2012;5:3-8.

7. World Health Organization. WHO Medicines Strategy: Countries at the core. Geneva; 2004. Available from: http://www.who.int/management/background_4a.pdf. [Last accessed on 31 Dec 2017]

8. Ajemigbitse AA, Omole MK, Erhun WO. Medication prescribing errors in a tertiary hospital in nigeria: types, prevalence and clinical significance. West Afr J Pharm; 2013. Available from: http://www.academix.ng/search/paper.html?idd=330001634 7. [Last accessed on 31 Dec 2017]

9. Arulogun OS, Oluwole SK, Titiloye MA. Prescription errors prevalent in four units of a university teaching hospital in nigeria. J Public Heal Epidemiol 2011;3:513-9.

10. Ogunleye 00, Oreagba IA, Falade C, Isah A, Enwere O, Olayemi $\mathrm{S}$, et al. Medication errors among health professionals in Nigeria: a national survey. Int J Risk Saf Med 2016;28:77-91.

11. Lazarou J, Pomeranz BH, Corey PN. Incidence of adverse drug reactions in hospitalized patients: a meta-analysis of prospective studies. JAMA 1998;279:1200-5.

12. Bates DW, Cullen DJ, Laird N, Petersen LA, Small SD, Servi D, et al. Incidence of adverse drug events and potential adverse drug events. Implications for prevention. ADE prevention study group. JAMA 1995;274:29-34.

13. Senst B, Achusim L, Genest R, Cosentino L, Ford C, Little J, et al. Practical approach to determining costs and frequency of adverse drug events in a health care network. Am J Heal Pharm 2001;58. Available from: http://www.ajhp.org/content/ $58 / 12 / 1126$ ?sso-checked=true. [Last accessed on 31 Dec 2017].

14. Leape LL, Cullen DJ, Clapp MD, Burdick E, Demonaco HJ, Erickson JI, et al. Pharmacist participation on physician rounds and adverse drug events in the intensive care unit. JAMA 1999;282:267-70.

15. Eldh AC, Almost J, DeCorby-Watson K, Gifford W, Harvey G, Hasson $\mathrm{H}$, et al. Clinical interventions, implementation interventions, and the potential greyness in the between-a discussion paper. BMC Health Serv Res 2017;17:16.

16. Smith WE. Role of a pharmacist in improving rational drug therapy as part of the patient care team. Ann Pharmacother 2007;41:330-5.

17. Avalere Health. Exploring Pharmacists' Role in a Changing Healthcare Environment; 2014. p. 1-30.

18. Oliveira De Melo D, Lusitana L, De Castro C. Pharmacist's contribution to the promotion of access and rational use of essential medicines in SUS. Cien Saude Colet 2017;22:235-44.

19. Swiatek D, Dally C. Not just dispensing: the unique role of pharmacists in an outpatient research pharmacy. Pharm Times 2016. Available from: http://www.pharmacytimes.com/publications/career/2016/ph armacycareers_may2016/the-unique-role-of-pharmacists-in-anoutpatient-research-pharmacy. [Last accessed on 22 Dec 2017]

20. National Universities Commision. Benchmark and Minimum Academic Standard-Pharmaceutical Sciences. Abuja: National Universities Commission; 2005. Available from: http://www.pcn.gov.ng/files/BMS.pdf. [Last accessed on 31 Dec 2017]

21. Shogbon AO, Lundquist LM. Student pharmacists' clinical interventions in advanced pharmacy practice experiences at a nonteaching community hospital. Am J Pharm Educ 2014;78:50.

22. Mersfelder TL, Bouthillier MJ. Value of the student pharmacist to experiential practice sites: a review of the literature. Ann Pharmacother 2012;46:541-8.

23. Campbell AR, Nelson LA, Elliott E, Hieber R, Sommi RW. Analysis of cost avoidance from pharmacy students' clinical interventions at a psychiatric hospital. Am J Pharm Educ 2011;75:8.

24. Pound MW, Miller SM. Written versus oral recommendations made by pharmacy students during internal medicine rotations. Ann Pharmacother 2007;41:772-6.

25. Lundquist LM, Moye PM. Resident physicians' acceptance of pharmacy students' pharmacotherapy recommendations during ambulatory care advanced pharmacy practice experience. Am J Pharm Educ 2009;73:145. Available from: http://www.ncbi.nlm.nih.gov/pubmed/20221338. [Last accessed on 31 Dec 2017]

26. Condren ME, Haase MR, Luedtke SA, Gaylor AS. Clinical activities of an academic pediatric pharmacy team. Ann Pharmacother 2004;38:574-8.

27. Stevenson TL, Fox BI, Andrus M, Carroll D. Implementation of a school-wide clinical intervention documentation system. Am J Pharm Educ 2011;75:90.

28. Pham DQ. Evaluating the impact of clinical interventions by PharmD students on internal medicine clerkships: the results of a 3 y study. Ann Pharmacother 2006;40:1541-5.

29. Slaughter RL, Erickson SR, Thomson PA. Clinical interventions provided by doctor of pharmacy students. Ann Pharmacother 1994;28:665-70.

30. Taylor CT, Church CO, Byrd DC. Documentation of clinical interventions by pharmacy faculty, residents, and students. Ann Pharmacother 2000;34:843-7.

31. Divall MV, Zikaras B, Copeland D, Gonyeau M. School-wide clinical intervention system to document pharmacy students' impact on patient care. Am J Pharm Educ 2010;74:14. 
32. Kucukarslan SN, Peters M, Mlynarek M, Nafziger DA. Pharmacists on rounding teams reduce preventable adverse drug events in hospital general medicine units. Arch Intern Med 2003;163:2014.

33. Nour AH, Khan M, Sulaiman AZ, Batool T, Nour AH, Khan MM, et al. In vitro anti-acetylcholinesterase and antioxidant activity of selected Malaysian plants. Asian J Pharm Clin Res 2014;8:271-3.

34. Bosma L, Jansman FGA, Franken AM, Harting JW, Bemt PMLA. Evaluation of pharmacist clinical interventions in a Dutch hospital setting. Pharm World Sci 2007;30:31-8.

35. Mukherjee S, Bhattacharyya A, Biswanath Sharma Sarkar B, Goswami DN, Ghosh S, Samanta A. Knowledge and practice of standard precautions and awareness regarding post-exposure prophylaxis for HIV among interns of a medical college in West Bengal, India. Oman Med J 2013;28:141-5.
36. Al Rahbi HAM, Al-Sabri RM, Chitme HR. Interventions by pharmacists in out-patient pharmaceutical care. Saudi Pharm J 2014;22:101-6.

37. Alderman CP, Farmer C. A brief analysis of clinical pharmacy interventions undertaken in an Australian teaching hospital. J Qual Clin Pract 2001;21:99-103.

38. S NE, R SK, MS NV. Review on clinically developing antibiotics. Int J Appl Pharm 2018;10:13-8.

39. Fahimi F. Implementation of a clinical pharmacy education program in a teaching hospital: resident-oriented documentation and intervention. Iran J Pharm Res 2010;9:297-302.

40. McGettigan P, Golden J, Fryer J, Chan R, Feely J. Prescribers prefer people: The sources of information used by doctors for prescribing suggest that the medium is more important than the message. Br J Clin Pharmacol 2001;51:184-9. 